American Journal of Economics and Business Administration 3 (2): 363-369, 2011

ISSN 1945-5488

(C) 2010 Science Publications

\title{
Islamic Conceptualisation of Knowledge Management
}

\author{
Muhamadul Bakir Hj. Yaakub \\ Department of Arabic Language and Literature, \\ Faculty of Islamic Revealed Knowledge and Human Sciences, \\ International Islamic University Malaysia, 50728 Kuala Lumpur, Malaysia
}

\begin{abstract}
Problem statement: This study is an attempt to address "The Fundamental Theory of Knowledge Management" from Islamic point of views, to draw the notion of "Islamic Worldview" of knowledge, especially in terms of understanding its nature in the reality of knowledge society as a step toward conceptualizing "Islamic Knowledge Management" (IKM) as an answer to the uncertainty situation of contemporary knowledge development, management and utilization especially for Muslim user and application. To obtain this, they have to explore new techniques and processing tools that helps them harness knowledge in according to their conceptual believe system, especially in term of knowledge investigation and sharing in which help them to improve their vicegerent (VG) status and humanistic relationship. Approach: Indeed, knowledge should be realised comprehensively. Thus, with the assumption that once knowledge is realized and managed, then it is possible to look at its behaviors, functions and process of development in the form of scientific realm. Hypothetically, if there were no single theory formulated to identify the nature of knowledge, then how it can be managed and achieved its goals. Results: In this regard, IKM as an Islamic system is intended for particular areas of application and objectives based on "knowledge intensive processing action" (KIPA), in which it is depending on some human expert intervention in order to establish a comprehensive and integrated organizational culture, commitments and management, or to better perform the process in producing a production, marketing campaigns, systems analysis and design and strategy in reducing operational cost and business risk, in improving decision making for strategic future development and identifying new technical approaches in problem solving, or even for the purpose to harmonize inter-cultural and personalities gaps within an organizational community. Conclusion: Obviously, knowledge classification is very much influenced by the way a society conceptualizes and realizes knowledge. Any classification will lead to a way of utilization. Therefore, any success achieved by a person was absolutely an output of his knowledge understanding and knowledge growth within himself. In this status, as a human, he might be influenced by a certain situation, limitation and constrain internally or externally that lead him to persuade either body knowledge or the functional usage of knowledge in making his own individual success i.e. user-centric based values.
\end{abstract}

Key words: Islamic, Knowledge Management, Sources and Understandings

\section{INTRODUCTION}

The issue of knowledge is very fundamental in Islamic teaching and practice. Based on the present situation and development, this study aims to explore and review the current literature on Knowledge Management KM, its conceptualization, application and implication output on individual development and organizational structure, particularly in relation to the humanistic survival and morality, in order to map out the rationale modeling strategies and objectives of KM application and practice. In other words, this study focuses on KM conceptualization, particularly on how Islamic Knowledge Management IKM approaches add value to KM modeling and practice.

\section{MATERIALS AND METHODS}

Knowledge in nature: The philosophy of knowledge is an old discipline. However, where does it stand today? In general, it can be understood loosely as the source of economy, power and prosperity. Focusing on the philosophy of knowledge and comparing its traditional sense with modern practice might lead us to discover some ways in which knowledge should be realized, managed and applied.

Obviously, the issue of criteria that determines what constitutes knowledge is indeed crucial. For that reason, the term used here is defined as a general concept that refers to the act of understanding any 
factual information wisely for any consideration of its truth or falsehood.

Knowledge, sciences and information: Due to some reasons, the terms "knowledge", "sciences" and "information" have been used synonymously or interchangeably in many contexts. They might be referred to a specific understanding, theoretical or practical or skill acquired by a person through experience or education and so on, i.e., there is no single agreed definition about them since the days of Plato up to the present time. The source of knowledge creation and its types, for instance, might be among the leading factors of defining redundancy and calamity.

As a concept, the term "information", on the other hand, has many meanings, from everyday usage to technical settings, in which it can be defined as closely related to the notions of having data of something and its representation. In this sense, it defers to "knowledge" as a concept referring to the ability in exploring and identifying the fact and figure of an information. Knowing the law of "clean air" as a gifted system that everybody has to take care of is a knowledge. Compare this to a person who becomes aware of "clean air" system after being informed by someone. In other words, (Goldman, 2006) regard knowledge as lucid information gained through the process of reason applied to reality or a successful evaluation of one's perceptions that lead to the use of reasoning objectively in drawing a valid and wise conclusion about the world.

Here, we have to consider the fact that the meanings of words, sentences and texts can change with time or cultural and even emotional conditions, i.e., space and span. According to Vamos (1990), the consequence of this fact is that a true logical proposition in one relationship can be false in another. Obviously, the issue of criteria that determines what constitutes knowledge is indeed crucial. For that reason, the term used here is defined as a general concept that refers to a wise understanding of factual information. Classical theories of knowledge however, would only recognize two categories of knowledge: True or false.

As symbolized by (Drucker, 1992) known as the Father of Management), the source of wealth is something specifically referred to as human knowledge. If we apply knowledge to tasks that we obviously know how to do, we call it productivity. If we apply knowledge to tasks that are new and different, we call it innovation. Only knowledge allows us to achieve those two goals after it is organized and applied. Therefore, a successful organization is the one which is successful in creating and sharing information and knowledge, as it leads to systematic organizational behaviors and strategies, i.e., $\mathrm{KM}$, as it was originally construed, focuses on the acquisition of knowledge before it can be structured, preserved and disseminated for the purposes of knowledge utilization, especially in the context of Case Based Reasoning (CBR) method as applied by (Kusrini et al., 2010) in describing the process of diagnosis analysis or reasoning for a particular decision.

Knowledge management: What is knowledge management? As an introductory step it is useful to distinguish here between raw information and knowledge. Raw information may be considered as widely available in users' hand, but only some users will be able to convert the information into relevant knowledge and to apply this knowledge to achieve their aims objectively. Michael (1994) regards the processes by which they do this are known as KM strategies.

$\mathrm{KM}$, as a natural phenomenon, is not a new issue in human history and practice. Consequently, there are various terminologies and definitions for it, starting from the broad process of locating, organizing and transferring, up to the information usage in sharing and networking. However, for our purpose of conceptualization here, $\mathrm{KM}$ is regarded as similar to "information management formulation" where the notion of systematic strategy of collecting, documenting and distributing knowledge whether explicit or tacit are included. As stated by Bakar (1998), "knowledge disorganized is life disorganized". In this sense, $\mathrm{KM}$ is not a new idea. It is a key element in a long strategy toward progress and success.

KM's component: KM as defined above can be observed as an existing process and application throughout human history with the exception of volume and structure, in which it composes of three important pillars:

- Knowledge that should be developed through exploration and searching

- Methodologies in which knowledge can be easily used, distributed and shared

- Effective users of knowledge as agents of change toward progress and success

Indeed, $\mathrm{KM}$ as proven by its pillars is not something that can be neglected by the entire human life. It is in fact, part and parcel of our growth and development, up to the extent that every individual should become an effective user of knowledge both in 
terms of planning ahead toward a bright future and also in terms of evaluating the past with the intention of securing future success or inspecting all aspects of current knowledge to conform with up to date requirements.

KM's functional criteria: In principle, the interest and awareness of KM's functional behaviors in contemporary human development have gained ground in several aspects of individual achievement, societal stability and maturity throughout human history, in which KM has been observed as having a specific role in the context of spatial modeling of life and stochastic reservoir modeling human life activities. Increasingly, these models go beyond the focus of a single data type and integrate numerous pieces of multi-disciplinary data each with their own complexity and often only fully understood by discipline specialists. For instance, the $\mathrm{KM}$ process base is usually used as a project specific vehicle for documentation, collaboration and creation of a quality assurance and quality control audit trail. Actually, as (Michael, 1998) and also (King, 2005) suggest that the central obvious role for any KM system is to serve as the primary repository for project documentation and application of any kind of information. Therefore, the functions of $\mathrm{KM}$ can be observed in many ways. However, there are three important conditional functions of constructing any $\mathrm{KM}$ modeling; they are:

- Identification of body knowledge, its categorization and types-knowledge should be searched and developed. The first task of KM is searching and identifying information that can help users get their jobs done, achieves their life objectives and activities

- Simplification of knowledge description and application-collection of information will be meaningless without good management methodologies in simplifying all types of knowledge for complete understanding and easy application on the real ground of usage practicalities

- Utilization of knowledge resources and its functional impact-user satisfaction should be the concern of any KM modeling and application. It can only be achieved by fulfilling user needs and tranquilities. In principle, the aim of knowledge discovery is for it users. In fact, people use information due to the fact that it can help them solve their problems, i.e., not keep them in trouble

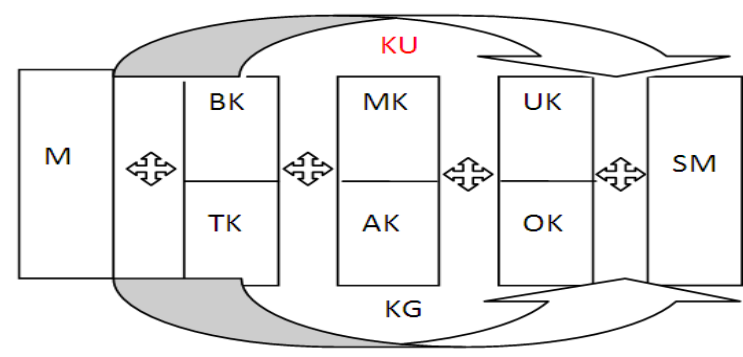

Fig. 1: KM functional model

In other words, what these pillars are intended to represent here is that $\mathrm{KM}$ is really able to enhance knowledge and also disseminate it among users, in which it leads them to become successful people. This model of conditional function for KM can be illustrated as follows:

$\mathrm{M}=$ Man; $\mathrm{BK}=$ Body Knowledge; $\mathrm{TK}=$ Type; $\mathrm{MK}=$ Methodology; $\mathrm{AK}=$ Application; $\mathrm{UK}=$ Users; $\mathrm{OK}=$ Output; $\mathrm{KG}=$ Knowledge Growth; $\mathrm{KU}=$ Understanding; SM = Successful Manager

The Fig. 1 describes the application of KM operational function in helping users achieve development goals and success in their life activities and productivities. Each of the elements represents a sub-process of $\mathrm{KM}$ that occurs when two or more individuals exchange knowledge, in order to move closer towards each other in the meaning they ascribe their success to knowledge function in making the events become workout and successful. In other words, $\mathrm{KM}$ can be used as a tool to store, retrieve, disseminate and manage information related to user needs.

Islamic conceptualization: The notion of Islam as a "manner of submission" to God the Creator is a useful reference point to begin a discussion on the Islamic conceptualization of KM. It is logical to assume that the Islamic notion of $\mathrm{KM}$ is related to and continuous with its notion of 'ilm knowledge) as the fundamental principle of conducts and practices. In Islam, as stated in the Quran, 2:239, the definition of knowledge is not confined to only epistemological concerns but also includes ethical truthfulness and other dimensions of objectivities.

Islam and knowledge: Islam is a religion of knowledge. As Sardar (1993) report that based on the Quran, 2:30-33 all Muslim regard knowledge as Godgiven to Mankind to be used as a point of reference and guidance for every theoretical endeavors to elaborate an 
Islamic paradigm and intrinsically related to the fundamental concept of obligation taklif as drafted by the Quran and the Prophetic traditions in structuring the Muslims' worldview toward all aspects of individual belief, societal behavior and cultural domain. Prophet Muhammad (peace be upon him) encouraged the acquisition of knowledge by saying "Verily, the men of knowledge are the inheritors of the prophets". The value of a man is the value of his knowledge.

Therefore, knowledge is not just a particular cultural production, neither an empty wisdom of an individual's experiences to include every single way of looking at things and acting accordingly, i.e., every way of life is based on a body of knowledge of a particular person and the universe he lives in and that knowledge determines his attitude towards his own self anfus and the universe afaq in general, besides setting norms to which his thoughts and actions must conform. All sort of beliefs, ideals and values-sacred or secular-spring from the worldview that emerges from the fund of knowledge at the disposal of a community. This is to say that knowledge is the root of culture and culture is the fruit of knowledge. Culture is like the knowledge on which it is based. Its value can be judged by the type of individuals it produces and of the society it establishes. It is not enough for Man to be born physically. One is made human through a cultural birth, through the inculcation of knowledge along with the belief, ideals and values it carries with it. The primary fact about Man is that he is not only a social but a cultural being. It is culture that gives meaning to what the Quran 2:29 calls the divine trusteeship amanah as vicegerent khilafah and makes Man worthy of the exalted position as moral agents of God on earth.

Just as knowledge is a means of attaining virtue, of gaining power over one's own self, so it is a tool for gaining power over nature afaq and harnessing its stupendous forces in the service of Man. But it is not the same knowledge that leads to self-conquest and to the conquest of nature. Knowledge of what is morally good for Man and knowledge of what is materially useful for him are two different kinds of knowledge. The former is the prerogative of religion, the product of revelation; the latter is the privilege of science, the product of inductive intellect which, as (Iqbal, 1986) is convinced, is made self-conscious by the recurrent appeal of the Quran to reason and experience. Since the knowledge of what is materially useful is as essential for Man as the knowledge of what is morally good, he needs both science and religion for steering through life in this world. What he needs is not science without religion, but science structured by religion. Conversely, what he requires is not religion without science and philosophy, but religion given intellectual content, wherever possible, by science as well as philosophy, without doing violence to its spiritual framework.

According to the Quran 96:1-5, human beings in principle are ordered to perform personal reading as a mechanism in seeking knowledge. It should be done in the Name of Lord, the Creator, the Most Generous who has taught by the Pen and has taught Man that which he knew not. The command here is not just to collect knowledge and information, but also direct man to organize, plan and manage properly the knowledge given to him. This concept of knowledge is illustrated in Fig. 2:

$\mathrm{KE}=$ Knowledge Existence; $\mathrm{KG}=$ Growth; $\mathrm{KM}=$ Management; $\mathrm{RK}=$ Revelation Knowledge; $\mathrm{AK}=$ Acquired Knowledge; HK = Human Knowledge; $\mathrm{KI}=$ Knowledge Investigation

The Fig. 2 describes that Muslims believe that knowledge originates from God and then is transferred to Mankind by various channels such as revelation, sense perception, reason and intuition as affirmed by Muslim epistemologists. This, according to (Al-Attas and Al-Attas, 1980) in turn implies that both induction from observation and deductive reasoning are valid methods of knowledge acquisition. In other words, knowledge is an existing phenomenon that Man has to explore and investigate. Once knowledge is known to a person, it becomes information to him, in which it becomes a science after it is applied by him and taught to others. According to the Quran, 2: 29-33, Man in his position as God's vicegerent on earth, he has to fulfill his task in investigating knowledge and developing its application as God created all those knowledge for him to be used and applied. Although some of the Quranic verses in this regard refer to Islamic knowledge, they are general in their meaning and thus can be used to refer to learning in general.

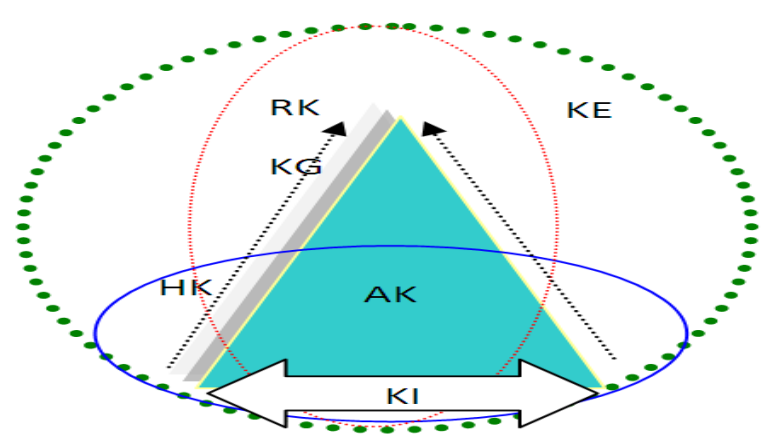

Fig. 2: Islamic conceptualization of knowledge 


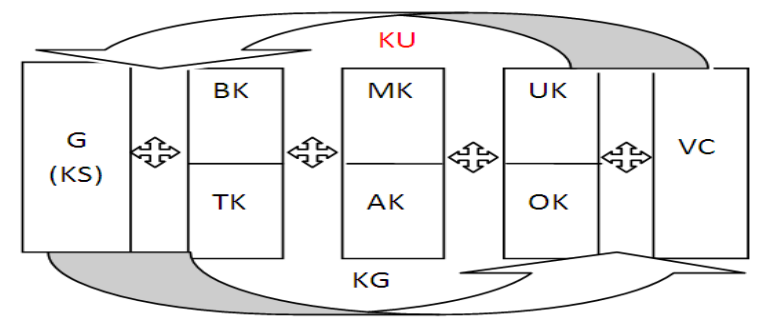

Fig. 3: IKM functional model

The output of an Islamic educational process will lead a learner to be a well-informed person who acts in accordance to the principles available at hand. This conception of knowledge regards education not merely as the acquisition of information or the capacity for explanation and analysis but also connects these processes to the command of God, to be an ethical being in carrying out the duty of a vicegerent on earth. With this view, it is hoped that it can serve as a step for the construction of a framework for an Islamic Knowledge Management Theory (IKMT).

Indeed, how humans view knowledge, its management and function, is a question imposed in the foundation of any ethical system. Some common views deny the existence of any purpose of knowledge other than those which create its role function in usage and application. Due to this behavior, they become different from other beings. These opinions basically view Mankind as an evolving animal physically and mentally.

Islamic knowledge management: As knowledge in Islam is intimately related to belief, knowledge, therefore, is part of faith. It is obligatory for all Muslims to pursue knowledge, to cultivate the various branches of knowledge and then to construct a suitable model of knowledge management in helping Mankind to become effective users of knowledge. Islam, in this regard, looks toward IKM's construction and application as important vision and mission for human development and survival as vicegerents of God, in which it should be bound by its intellectual wisdom, spiritual strength, mental ability and even socio-cultural conditions of scientific creativity. As noted by (Abdelkrim et al., 2010) that Information Retrieval (IR) is an example of developing an effective knowledge user, especially in term of relocating and delivering knowledge in according to a specific needs.

IKM's functional criteria: As discussed in 2.1.2, KM is composed of three elements: Body of Knowledge (BK), Methodology of Knowledge (MK) and
Knowledge-base Users (KU). IKM however, has another additional element that is the Knowledge Source (KS). In this case, knowledge is considered as co-existing with Mankind. Therefore, their duty is to search and develop that knowledge according to their needs, urgencies and suitability. This approach is meant as a straightforward manner of looking into KS which is brought to light through interpretation based on an expert's specialization or collective constructive finding which is known as Ijtihad.

The output of this process should be valuable and convincing enough to appeal to the rational mind that inevitably appreciates their worth to practically apply them to enhance the effectiveness of productivities and achievements.

These elements and their functional criteria of IKM can be illustrated in Fig. 3:

$\mathrm{G}$ = God; KS = Knowledge Source; $\mathrm{BK}=$ Body Knowledge; $\mathrm{TK}=$ Types; $\mathrm{MK}=$ Methodology; $\mathrm{AK}=$ Application; UK = Users; $\mathrm{OK}=$ Output; $\mathrm{KG}=$ Knowledge Growth; KU = Knowledge Understanding; $\mathrm{VC}=$ Vicegerent.

The Fig. 3 describes the application of IKM and its operational function in helping users achieve the success as vicegerents of God. The hypothesis here is based on Quran, 39: 38; 41: 53 assertion that when human beings are able to manage knowledge for themselves as structured by IKM, they will be able to recognize the greatness of Allah, the Creator of the universe.

\section{RESULTS AND DISCUSSION}

$\mathrm{KM}$ as discussed in this study is an import determination factor for individual success and also organizational performance whether the term "KM" has been used explicitly or not, it indeed transforms an individual to be a $\mathrm{KU}$, it helps organizations to gain competitive advantage and effective working through systematic sharing procedure and workflow in which it lead to organizational improvement, responsiveness, innovation, competency and efficiency. According to Marzanah 2010, the identification of this factor will be very meaningful, especially with the ability of transforming tacit knowledge and competencies to become knowledge assets.

Based on similar principle, (Ahmad et al., 2010) pointed out that tourism is among the issues which are of cultural and economic importance for governments and also private agencies to pay attention on it. This will only be achieved through good understanding of 
KM methodological framework and applications, especially in determining the tourism objectives and strategies. In fact, it is considerably an importance component of social development and civilization profound. Therefore, most countries look at the tourism as a necessity and make use of all their capacities and facilities to get to their intended interests and privileges.

Islam et al. (2010) on the other hand discussed his observation on the influence of trade rules on the components of sustainable development and sustainable management. The direction and significance of impacts depends on the nature of the policy and regulatory frameworks which are under-developed or welldeveloped capacity for policy analysis and implementation. Sustainable forest management for instance, implies the sustainable utilization of forest resources for the benefit of communities and states. The concept not only aims to maintain the value of forest resources, but it also has a huge potential for creating employment, income and wealth for the populations and states concerned comprehensively.

Finally, some holistic principles of IKM application can be listed from the above discussion:

- IKM conceptualization as drafted in this study is an attempt toward knowledge realization from an Islamic perspective

- IKM users have an optimistic view upon knowledge existence, its boundaries, categories and types. Consequently, they deal with knowledge as part and parcel of their life activities and routine

- IKM users should not have to choose between knowing a little about a lot or a lot about a little. They should be able to concentrate mostly on what they need to know and when it is needed to identify any related additional condition in which it requires another inspection of the environment designed for its usage. On this basis, Quranic verses have been revealed in staged process and not in one whole package

- Besides self-satisfaction as an important factor of managing knowledge, IKM also focuses on users' safety. In this context, (Singh, 2009) used the term 'Precautionary Principle' in which he emphasizes on the limitation of human knowledge in realizing the unseen phenomena of the existence. This is among the factuality of Mankind, that he will remain narrow or short minded, forgetful and even careless some times by which his nature intuitively knows whether he is able in managing his own knowledge well or otherwise and leads him to achieving the status of vicegerent of God successfully

- Mankind is always facing problem after problem in all stages of his life. For this reason, he searches for solution and evaluation as an integrated approach and up-to-date investigation in achieving comprehensive problem solving. In this regard, (Mukherji, 2009) plead for the needs of considering the intergenerational equity in consuming and depleting our contemporary resources by identifying the most effective KM's modeling framework.

\section{CONCLUSION}

This research is an attempt to investigate the concept of KM as a step approaching IKM conceptualization, to identify their components and functional behaviors. In comparison, we observe that the penetration of KM movement strategies starts with users and ends with users internal or external, i.e., its functional modeling is taking more user-centric base behaviors in many multi-disciplinary management efforts. IKM, on the contrary, starts with knowledge recourses for the purpose of user development and then ends up again with the source of knowledge as user evaluation and confirmation in searching effective usage and application, i.e., its functional modeling is more toward recourse-centric base behaviors where all Knowledge Understanding and Knowledge Output should be a reflection of Knowledge Source representation physically or hermeneutically constructed. Therefore, the need for IKM is paramount to ensure:

- Inclusion of all types of knowledge, including abstract or revelation knowledge reflected in conformities within the modeling process

- Defining a modeling process that comprehensively covers the reservoir issues humanistic in nature while leading to "fit-for-purpose" results in a defined time space and span

- Storing knowledge generated force during the modeling process to ensure adequate and efficient model adoption and adjustment to suit specific workflow

Finally, it is obvious that managing knowledge requires an appropriate tool. Each and every tool has its own function and objectives. Therefore, IKM is very fundamental for a Muslim manager in achieving his managerial function, progress and productivities. 


\section{REFERENCES}

Abdelkrim, B., M.K. Kholladi and B.L. Doan, 2010. PRESY: A context based query reformulation tool for information retrieval on the web. J. Comput. Sci., 6: 470-477. DOI: 10.3844/jcssp.2010.470.477

Ahmad, P.A., M. Shabanifard, A. Hosseini and O. Soltanipour, 2010. Study of tourists' rights in iran with emphasis on urban tourist rights. J. Soc. Sci., 6: 340-349. DOI: 10.3844/jssp.2010.340.349

AL-Attas, S.M. and A.-N. Al-Attas, 1980. The Concept of Education in Islam: A Framework for an Islamic Philosophy of Education, Kuala Lumpur: Muslim Youth Movement of Malaysia (ABIM); (reprint, Kuala Lumpur: International Institute of Islamic Thought and Civilization (ISTAC)) www.mef-ca.org/files/attas-textfinal.pdf

Bakar, O., 1998. Classification of Knowledge. Islamic Texts Society. ISBN: 13: 9780946621712, pp: 330.

Drucker, P.F. 1992. Managing for the Future. 1st Edn., Butterworth-Heinemann, Oxford, ISBN: 13: 9780452269842, 978-0452269842, pp: 73.

Goldman, A.I., 2006. Simulating Minds: The Philosophy, Psychology and Neuroscience of Mindreading. 1st Edn., Oxford University Press, USA., ISBN: 13: 9780195138924, pp: 364.

Iqbal, M., 1986. The Reconstruction of Religious Thought in Islam. Saeed Sheikh, M. Ed., Institute of Islamic Culture, Lahore, pp: 101. http://www.library.wisc.edu/guides/soasia/religion/ islam.html
Islam, R., C. Siwar and S.M. Ismail, 2010. Impacts of trade and environment on sustainable development. Am. J. Environ. Sci., 6: 11-19. DOI: 10.3844/ajessp.2010.11.19

King, D.J., 2005. Humanitarian knowledge management. Proceedings of the 2nd ISCRAM Conference, Belgium, pp: 1-6. http://ebiz.uoregon.edu/poms2008/FullPapers/0080047.pdf

Kusrini, S.H., R. Wardoyo and A. Harjoko, 2010. Differential diagnosis knowledge building by using CUC-C4.5 framework. J. Comput. Sci., 6: 180-185. DOI: $10.3844 /$ jcssp.2010.180.185

Michael, E., 1994. NGOs in the age of information. IDS Bull., 25: 117-24. DOI: 10.1111/j.17595436.1994.mp25002013.x

Michael, E.D.K., 1998. From intellectual capital to knowledge management: What are they talking about. INSPEL, 32: 222-233. http://forge.fhpotsdam.de/ IFLA/INSPEL/98-4koem.pdf

Mukherji, A., 2009. The role of trade regulations in the sustainable management of natural resources. Am. J. Econ. Bus. Admin., 1: 296-302. DOI: 10.3844/ajebasp.2009.296.302

Sardar, Z., 1979. Paper, Printing and compact disks: The making and unmaking of Islamic culture. Media, Culture Soc., 15: 43-59. DOI: 10.1177/016344393015001004

Singh, I.P., 2009. Trade and precaution: Their progressive interlace. Am. J. Econ. Bus. Admin., 1: 320-333. DOI: 10.3844/ajebasp.2009.320.333

Vamos, T., 1990. Computer Epistemology. World Scientific Publishing Company, ISBN: 109810203799, pp: 150. 